Scott Loren

\title{
Frankenstein's Legacy: Discursive Thinking in the Economic Paradigm
}

Thinking revolution as a reversal in the order of things, Foucault points toward the status of literature changing in its relationship to knowledge during the nineteenth century, when it "ceased to belong to the order of discourse and became the manifestation of language in its thickness" (Foucault 1998, 265). Where knowledge in the Classical period is characterized by narrative continuity, with the rise of institutionalism and industrialism it was reconstituted as "a sort of general and systematic taxonomy of things" (ibid. 264). This reversal in order sets the stage for reflexive modernity as a fundamentally economic paradigm. Insofar as we can speak of social scientific functionalism in modernization processes (Habermas 1996), we might think of the economic paradigm as constituting a systemization of processes according to principles of automation; particularly in the relational dynamics of human-machine interaction (HMI). This was true for the period Foucault addresses, as it is for our present moment of conjunctural change. Mediated as it is through advances in machine learning and natural-language cognition, we may be obscure witnesses to another reversal in the order of things, back toward discourse but with a difference. While discourse has reassumed a function of technologizing HMI productivity, modernity's current iteration focuses on the cultivation of language cognition patterns through the algorithmic management of HMI.

The current moment of reversal has been facilitated through the conjoined affordances of digital media convergence, inclusive network recursion, data stockpiling, user complicity, and free algorithmic labor. In an expansive machine environment where traces of human presence appear as transient networks of synaptic association and loops of programmatic action, we work in conjunction with intelligent machines and infrastructures to produce resources for the real evolution of those machines and infrastructures. This peculiar reversal in HMI economies heralds a "second machine age" (Brynjolfsson and McAfee 2014). While the fact of conjunctural change in the present is tangible, and while its having something to do with the affordances noted above seems sensible, close proximity makes it difficult to perceive what the near-future contours of reflexive modernity might be. As a revolution in machine intelligence and 
cognitive labor, this is particularly true for its potential impact on the status of knowledge.

Following Luhmann's suggestion that an understanding of present situations might be facilitated through comparison to "older forms of descriptions of the future" (Luhmann 1998, 64), I want to read three scenes of conjunctural storytelling as a technique for screening reversal in the order of thinking things. My analysis seeks to provide a heuristic for thinking the limits of knowledge in transitional periods, and the critical role discursive cognition has played in the representation of HMI. Illustrating a particular configuration of techno-epistemic shift, each scene evidences an aesthetic of heightened self-reflexivity. Part of what makes them exceptional is their ludic character, or the way they try to trick the reader into or out of perceptual habit. They each employ a reflexive trope accompanied by a feint or ruse that fundamentally reorganizes the text's aesthetico-ideational economy once discovered. They do so with such performative acuity in their respective framing of the conjunctural moment that, more often than not, these ruses go unnoticed.

The first scene is from Mary Shelley's Frankenstein; or, the Modern Prometheus (1818). Against the background of Hobsbawm's Dual Revolution (Hobsbawm 2006), Frankenstein prototypically presents the conjuncture of industrialization technologies and institutional unrest through the trope of the frame. Its ruse is found in the elliptic references to the mechanical weaving frame and revolutionary frame breaking in the Luddite uprisings. It is a period where the invention of the flying shuttle for mechanical looms revolutionized the textile-weaving industry; once the largest industry in England. With the introduction of punch-card technologies shortly after, the Jacquard loom was an important forerunner of modern computer programming; and as such an originary iteration of programmatic HMI.

The second scene is from Alan Turing's "Computing Machinery and Intelligence" (1950). Contextualized by the rise of intelligence as a cultural form following the era of "total war" (Hobsbawm 1996), and central to the emerging socioeconomic logics of cold war and post-imperial military-industrial capitalism, Turing's seminal text represents the conjunctural moment through the conceptual trope of the game. Its ruse can be found in the ludic double inversion of deceptive imitation, where intelligent machines assume human roles and humans are programmed to function like machines. 
The third scene is from Google's corporate rebranding and restructuring. The company's public announcement in 2015 hails the onset of a language-cognition driven “A.I. awakening” (Lewis-Kraus 2016), where intelligence explosion results from datastockpile accessibility and advances in the capacities of inclusive-network computing. Turing prognosticated these conditions of a massive expansion in decentralized storagememory, processing-power and the programmatic introduction of random elements that, together, might facilitate thinking in universal machines around the turn of the century. The public announcement of Google's restructuring and rebranding represents the conjunctural moment of machine intelligence Turing foresaw through the conceptual trope of naming. Its feint is in the deflection of attention through linguistic ambivalence, affective impulse and emotive attachments to formative moments of language acquisition.

\section{Textuality - Shelley's Frames}

Mary Shelley's Frankenstein is concerned with conjunctural transitions of late $18^{\text {th }}$ century Europe integral to the economic paradigm: novel modes of societal organization (institutionalism), ideological shifts of secularization and individualism (Enlightenment humanism), the lack social equality (slavery and emerging class society), epistemic shifts toward scientific empiricism (and German idealism), and the transition from agrarianism to industrialism. With such an abundance of novelty, a common misreading has been to understand too narrowly the scope of out-of-control technologies this story addresses. However, Shelley is careful not to address these things by aesthetic habits of exposition. Her depictions of technosocial automation are articulated by framing the limits of knowledge; and through what Barbara Johnson termed "explanatory ellipsis" (Johnson 2014, 6). As she suggested, Shelley's slight of hand is not to show the reader what he is unable to see, but to show him his condition of not seeing (ibid.). This indirect reflection on technosocial transition through techniques of framing and elision is evident in the story's title.

The Modern Prometheus refers to classical mythology and the fatalistic episteme of tragedy, while bringing these into a contemporary context of early scientism through an indirect reference to Benjamin Franklin's experiments in electromagnetism. The hidden reference is made by way of Kant, who famously referred to Franklin as a modern Prometheus (cf. Rogers and Stevens 2012). Mobilizing the Prometheus myth in reference to Franklin provides an ideational framework of foreshadowing for diegetic 
character and plot development, and for thinking the extra-diegetic state of technosocial innovation as radically disruptive: as progenitor of the human race and life-giver through the originary technology of fire, Prometheus is associated with the pursuit of scientific knowledge and the consequences of obtaining it by breaking the frame of possibility. Its outward references to Prometheus and Franklin help to construct an initial frame for the eponymous narrator, Victor Frankenstein, as well as for the fact that the other narrator - Frankenstein's monster - is never named.

Ascribing Frankenstein narrative authority, the story becomes one of a young scholar from an affluent family whose demise results from the Promethean usurpation of occult knowledge and divine technology. As a student of natural philosophy who collects disparate body parts, assembling them into a super-human physical frame and animating it with the secrets of electromagnetism, Frankenstein is unambiguously depicted as a modern Promethean-Franklin. However, it is also possible to take the omission of the other main character-narrator in the story title as a gestural inclusion of that which cannot (yet) be named. Recalling Foucault's taxonomy of things, naming as an act of empirical order is a recurrent trope throughout, and is intelligible in Shelley's framings of genre, narrative voice and self-description.

Shelley aligns structural shifts in narrative framing with shifts in narrative voice and generic style. The story's three narrators are Robert Walton, Victory Frankenstein, and the nameless creature. Walton begins the tale with a series of letters addressed to his sister: "You will rejoice to hear that no disaster has accompanied the commencement of my enterprise" (Shelley 13). While the letters function according to literary conventions of the frame narrative, opening with the letter genre also looks outward beyond the diegetic frame, providing a mirror for letter writing as a popular genre concomitant to advances in transportation technologies and the advent of mass literacy (cf. Allen 2008). The literacy, letter writing and mobility implicated by genre at this outer narrative frame also constitute crucial thematic elements in the story's development and in Shelley's reflexive ruse on communicating conjunctural change.

Following Walton's fifth letter, narrative voice shifts to Victor Frankenstein, whose autobiographical account of events are told in a confessional manner. Victor's manic admissions of glory and guilt gesture beyond the diegetic frame at Rousseau: a fellow Genevan confessionist, educational reformer and secular rationalist. Like Walton's narrative, Victor's story is a frame for the historical turn towards individualism, a point Shelley accentuates by beginning with the first-person subjective 
pronoun: "I am by birth a Genevese, and my family is one of the most distinguished of that republic. My ancestors had been for many years counsellors and syndics, and my father had filled several public situations with honour and reputation. He was respected by all who knew him for his integrity and indefatigable attention to public business" (Shelley 30). As David Shishido notes, Victor's autobiography reiterates the selfreflecting Hegelian subject and "divided self-consciousness" (Shishido 2011, 118) already established with Walton, but where Walton's narrative calls attention to the conventions of letter writing in the first instance, Victor's makes the new orders of class society intelligible. With his genealogical claim to authority through heritage, Victor's $I$ appears to present a (Hegelian) "self-understanding of liberal society which is based on the non-selfish parts of the human personality, and seeks to preserve that part as the core of the modern political project" (Fukuyama 1992, 145). If Victor forgets his debt to society in the end, it is because he has lost the capacity to recognize his own contributions to the new world around him.

Contrasted to both Walton and Victor, the creature is singular in its total lack of heritage. With no ancestry, no name, no social context, and no mirror to its sense of self, the creature occupies a position of radical alterity (cf. Loren 2004/2018). If Walton's other-directed "You" at the outermost frame represents an empathetic social sensibility, and Frankenstein's self-determined "I" represents a state of aristocratic self-awareness, embedded at the center of these is a nameless thing free of history and without specificity. This is well articulated in the creature's first words as it assumes narrative voice at the story's innermost frame: "It is with considerable difficulty that I remember the original era of my being; all the events of that period appear confused and indistinct" (Shelley 98).

Emphasizing the quality of thingness by beginning with the pronominal distinction $i t$, the creature's self-story is one of providing things with names. As "a poor, helpless, miserable wretch" that "knew, and could distinguish, nothing" (Shelley 98), the creature's world is one of manifold lack. Here we see that the creature's lack of narrative continuity hinders temporal order, while the lack of categorical distinction disallows empirical knowledge. As such it finds itself between two spaces of negation: the obscured recollection of an irrevocable past, and an immanently unrecognizable present. With these representational parameters, Shelley gestures toward the conjunctural moment of dual revolution, moving from the sovereignty of the Word to that of secular institutionalism, and from the scene of the agrarian narrativity, with its 
chrono-logical orders, to the schematic discontinuities of industrialism. While Shelley resists conventional modes of aesthetic articulation that might allow for a simple identification of these parallel conjunctural scenes (cf. Loren 2018), they are both formally mediated through the shared techniques of shifting narrative voice and the double-frame story. With two narrative frames outlying the mise-en-abyme of the creature's story, we thus have a performative gesture toward the double mediation of self at the outset of reflexive modernity. On the one hand the modern subject appears to be produced as a technosocial object of institutional order. On the other hand the same individual disappears into the nameless masses of Lumpenproletariat anonymity that is abstracted into a prosthetic function of industrial production (cf. Gardener 1994, Montag 2000). If the double frame narrative and shift in voice signal the dynamic compressions of dual revolution mediating modernity per se as well as the modern self, the historical lack of recognition characterizing new class relations, narrative discontinuity, and alienation are symbolically inscribed in the creature's physical frame.

\section{In(di) visible Bodies: framing frame-breaking}

As Bouriana Zakharieva has suggested, one of the most striking characteristics about the creature is its "composite body" (Zakharieva 1996, 416). Constructed with "materials" from the "dissecting room and the slaughterhouse" in Frankenstein's "workshop of filthy creation" (Shelley 52), this bodily frame is the symbolic site of technosocial conjuncture. In its materiality of dis-membering and re-membering, it conjoins disparate members of other bodies to create a paradox of absence in presence. The creature's remembered body thus synthesizes life and death, incorporating within it an opposition of things that allow it to accommodate an array of contradictions: "intellect and feeling; a humanist disappointment of scientific progress; the moral consequences of science probing into the secrets of life/nature and the Christian implications of this problem; the utopian visions of a new man (a new society) as a direct ideological response to the political ideas of the French Revolution, etc." (Zakharieva 741).

With the specular disjuncture of the creature's composite body, its inscrutable production in a "workshop of filthy creation", and Victor's repeated failure to recognize it as a subject in language, we can now turn to the question of visuality, mobility and industrial production relative to the creature's symbolic value through explanatory ellipsis. As Chris Baldick has argued, early receptions of Frankenstein read the 
portraiture of out-of-control technologies with the creature as an archetype of class oppression and the laboring masses. Building on Baldick's reading, Edith Gardener notes that, in addition to being "interpreted as an allegory of the French Revolution" (Gardener 1994, 71), Frankenstein can also be understood "as a depiction of the contemporary situation in Britain in terms of the Luddite uprisings which occurred between 1811 and 1817" (ibid. 70).

Gardener makes a compelling argument for how Shelley's writings thematically and linguistically "make reference to the Luddites" and the widespread "fear of revolution" (ibid. 70-1). The focus on discourse and failed diplomacy through language in the diegesis finds historical parallels in the textile labor movements, whose failure to gain recognition through diplomacy and discourse subsequently resulted in more radical measures that sought recognition through revolt. The repeated failures on behalf of employers and parliament to respond to petitions are striking in resemblance to the creature's pleas for recognition that remain strangely unintelligible to Victor, even when he must suffer the consequences of not taking responsibility for what he has called into the world. Gardener also points toward the historical locations of resistance. Known as "the Luddite Triangle," the uprisings were directed at framework knitting and lace trade in Nottinghamshire, Leicester and Derbyshire; the cotton trade in Lancashire and Cheshire, where industrial power looms were implemented; and at the shearing and wool industry in Yorkshire (Gardener 73). Notably, Victor's travels (taking place in the storyworld of the late 1790s) move directly through major sites of HMI commercial production, including the Luddite triangle; and yet no industry is visible.

There are thus two major sites of explanatory ellipsis intelligible in their specular and discursive occlusion. The threshold space of Victor's "workshop of filthy creation" is a proto-industrial factory where the bodily frame is automated, but whose processes and attributes are discontinuously portrayed. As Warren Montag suggests, this specular-discursive occlusion is mirrored in Victor's travels through Paris and London, and to the Lake District via Edinburgh, which presumably take him through Lower Scotland, Yorkshire and Manchester. Moving through the site of revolutionary France and what with increasing clarity was becoming the cradle of automated industry, there is no sign or mention of these. With the creature's animation, they are what Frankenstein symbolically calls into existence: "If the modern (the urban, the industrial, the proletarian) were allowed to appear, the monster would no longer be a monster... Instead, the mass is reduced to the absolute singularity of Frankenstein's creation, which 
is therefore not so much the sign of the proletariat as of its unrepresentability" (Montag $2000,395)$.

While narrative framing techniques and the creature's bodily frame symbolically gesture at the new technologies of automated frame weaving, invisibility at these and other locations serves as a ruse in which Shelley additionally gestures toward representational failure through explanatory ellipsis. Like the creature, who - with his broken frame of a body - remains unrecognizable beyond the human detritus left in its wake, the textile workers' lack of equitable social representation becomes infamously memorable in rebellious acts of frame-breaking; a political undertaking whose symbolic value is often mistaken for material pragmatism. As if deficiencies in social diplomacy could be solved by displacing agency onto a few dumb machines. The problem is not only one of material displacement in a genealogy of automated HMI, but concomitant displacements of representation and recognition throughout the economic paradigm.

\section{Analogy - Turing's Games}

The conjunctural moment of post-industrial-scale warfare in 1950 was outwardly marked by international diplomacy and decolonization, and inwardly marked by structural transformations giving rise to a new world order. War-era decolonization led by no means to a forfeiture of infrastructural-material resources that had been set in place over the course of industrial imperialism. Acting as a conduit for the transition from New Imperialist state monopolies to post-war state capitalism, technosocial transitions in this era allow for their re-institutionalization: "Post-war capitalism was unquestionably... a 'new' version of the old system" (Hobsbawm 1996, 270). Under this dramatic double mask of diplomacy and protectionism, decentralized extensions of politico-economic power cultivated a geo-politics of Cold War espionage, surveillance, and strategic deception, and are the second site of reversal in reflexive modernity's automation economies.

According to Hobsbawm, "Turing's celebrated paper of 1935, which was to provide the foundation of modern computer theory, was originally written as a speculative exploration for mathematical logicians. The war gave him and others the occasion to translate theory into the beginnings of practice for the purpose of codebreaking" (ibid. 527). Ending the era of industrial-scale warfare, military intelligence converged with machine intelligence in the use of analog-computer cyphering machines. From this point onward, the automation of mechanical computation and 
programmatic code would be central to transitions of the information age and knowledge economy. The shifts from total war to cold war, and decolonization to cold colonialism thus constitute a techno-epistemic shift from industrial production to computational intelligence. Published in October 1950, Turing's "Computing Machinery and Intelligence" marks these transitions in a conjunctural story of ludic deception characteristically reflexive of the technosocial moment.

\section{Language Games: intelligence in the post-war moment}

Turing's very first gesture in "Computing Machinery and Intelligence" is to open a space of ambiguity: "The Imitation Game. I PROPOSE to consider the question, 'Can machines think?"' (Turing 1950, 433). Unlike a directly posed question, this disingenuous proposition generates issues of decidability, first implying there may be a problem with the content of the query, thus requiring consideration, and next that there may be a problem in the query's formulation, which requires further specification prior to a reflection on the query that appears to be posed. Once these issues are clarified, a consideration of the query proper might be pursued. In programmatic fashion, and with no lack of humor, Turing addresses each of these elements. The Imitation Game opens with a ruse on the reliability of natural language, and thus on the epistemic status natural-language cognition: the consideration "should begin with the definition of the terms 'machine' and 'think"' (ibid.). Not only is there ambiguity built into words as signs, there is also the problem of consulting the proper authority to determine the taxonomic status of these words: should meaning be provided through "a statistical survey such as the Gallop poll?” (ibid.).

Here we have an initial glimpse of the contest at hand: human thinking as lexical ambivalence and idiosyncratic association versus machine logic as statistical enquiry (into natural language cognition) to determine truth-value through majority opinion. In these opening lines, Turing has already reversed agential roles, divesting humans of their capacity for rational thought, and investing machine-computational procedures (survey calculations) with the capacity to mediate an expression of collective truth. This is precisely the function of language as a social technology: a lexical sign can be attached to a set of ideas or quasi-objects and employed with identifiable meaning insofar as its collective negotiation limits the set of associations in conventional usage. As such, Turing displaces human agency and ascribes the work of natural language processes to computational procedure. 
Having nearly considered the question can machines think? Turing returns to it in yet another deferral: "I shall replace the question by another, which is closely related to it and is expressed in relatively unambiguous words" (ibid.). Note here that Turing omits the substantive term that another should qualify, allowing his reader to fill in this lexical blank with the implied antecedent question: I shall replace the question by another question. Grammatically and idiomatically, it is a logical assumption. Having moved from the question of machine thinking to the problem of linguistic ambiguity, however, Turning does not replace the original question with another question. Capitalizing on the relative ambiguity of words, he replaces the initial consideration, as a problem of determinacy, with a "new form of the problem" (ibid.):

...the problem will be described in terms of a game we will call the 'imitation game'. It is played with three people, a man (A), a woman (B), and an interrogator (C) who may be of either sex. The interrogator stays in a room apart from the other two. The object of the game for the interrogator is to determine which of the two is the man and which is the woman. (ibid.)

A string of game parameters and sample scenarios ensue. As they develop, we find there is not only a single objective - that of the interrogator - but also ones for the man (to trick the interrogator into thinking he is the woman and B is the man) and the woman (to help the interrogator correctly determine which is the woman and which the man). Following this implicit gesture toward the cultural codification of men as deceptive and women as supportive, Turing then introduces a third conceptual parameter in yet another return to his original query:

We now ask the question, 'What will happen when a machine takes the part of A in this game?' Will the interrogator decide wrongly as often when the game is played like this as he does when the game is played between a man and a woman? These questions replace our original, 'Can machines think?' (ibid. 434)

At this point, the imitation game becomes recognizable as an iteration of the Turing Test. The basic goal is to test whether a computer can deceive a human into believing it is communicating with another human. As critics and proponents have argued, at stake is not a question of thinking in the conventional sense; but the tasks of imitating, deceiving, interpreting, and evaluating (cf. Warwick and Shah 2016). To what extent, then, does this facsimile (L. making alike) through analogy (L. sequence of speech) constitute valid comparability between potentially thinking yet disparate things? 
Programmed as they are into the structure of his proposal, Turing anticipates such criticisms, addressing them in terms of what we mean by thinking, intelligence, and intellect; by problematizing distinctions between types of machines, as well as between machines, technology, and technique; between human machines, gendered machines, conceptual machine and material machines; and in particular in terms of knowledge as situated in multitudinous ways. Thus, aesthetic habits of distinction between the conceptual and the material, and between thought and action, are also generally (if implicitly) problematized. Moreover, Turing addresses the question of how significant the differences between conventional notions of thinking and imitation are for the experiment at hand. If the test is successful, what does it mean for a human to not know the nature of the entity it is communicating with? What does it mean for a machine to know how to imitate a human to the extent of being indistinguishable? Further on, Turing addresses the possibility of digital computers that can learn, make informed changes to their own programs, and thus also devise innovative strategies for problem solving. He returns yet again to the original question of machine thinking, theorizing that universal computational machines would be able to evaluate a problem and generate a solution through "scientific induction" (Turing 458). Thirty years later, the first functional inductive inference program was developed by Ehud Shapiro; and Inductive Logic Programming is now a standard category for cognitive-model machine learning and logic programming.

Having opened with a language-cognition game of ambiguity, there is something like ludic wit produced between what the paper has historically achieved (its practical contribution to machine intelligence) and what it discursively displays in its performance of language games. Turing provides sites of inductive logic throughout, ranging from the broad play of lexical ambivalence and linguistic deception (for instance, where the reader assumes that one question will be replaced by another question) to the context of programmatic ludic deception: a person can or cannot guess if her interlocutor is a machine or human based on what is divinable through a series of questions and answers.

This type of ludic analogy is present in more dramatic ways as well. For example, Turing short-circuits the game to some extent early on by implying differences in the communicative and cognitive habits of men and women. Where the original distinction is implied as one between humans and machines (can machines think?), splitting humans into a dual and differentiable set (men and women) impacts the range 
of what can be deduced as likely or possible. By subsequently switching out the man's position and replacing it with a machine, Turing partially preempts the accusation that imitating human thinking is not the same as being capable of human thinking, even if it is in some ways comparable. Now, instead of two comparable terms that might or might not be equated depending on how statistical data determines the performance of each, there are three terms, two of which are generally recognized as imbued with the capacity for thought (men and women), though the habits of language-cognition may differ between the them (cf. Warwick and Shah 2016, 28-35). What began as a twoterm equation (like or unlike) now has a third term concomitantly valorizing all possibilities: the language-cognition of women and men is both like and unlike. This ludic tactic impacts the parameters of possible truth-values. If human thinking can be both like and unlike itself, then a machine that appears to be like and yet is unlike a human has greater claim to validity by analogy.

\section{Turing Complete?}

There is a still more prominent analogical inversion in Turing's reflexive and performative ludism. We have seen that he subtly establishes covert double games from the beginning. This is also true for the imitation game itself, where machines imitate humans to help human cognition reflect on the possibility of machine thinking. In this mise-en-abyme of a game within a game, the question of a machine's capacity to perform intellectual tasks on par with human intellect becomes a question of how to qualify intellectual tasks per se in much the same way that, for the question of machine thinking, we must first address the question of what is meant by machine and think. From the beginning, Turing opens the double game of language-cognition ambiguity, relying on the likelihood of a lack in general consensus: incapable of agreeing on meaning, humans do not think alike regarding meanings of thinking and machine. An initial game within the game thus arises in relation to an epistemological impasse inherent in natural-language cognition. However, the condition is only particular to linguistic meaning if we also assume an inextricable relation between human thought and natural language.

On one hand, the reader should agree that the problem of consensus is a pragmatic real issue when seeking to address the question of machine intelligence. Accordingly, Turing reformulates the question of machine intelligence as a problem-solving exercise with the capacity to achieve the following: 
○ remove ambiguity by,

o introducing a set of non-ambiguous rules and commands that,

- enable a scenario of interactive performance around

$\circ$ the exchange of information, thus,

$\bigcirc$ generating a new set of information that is

○ quantifiable and has evaluative use.

On the other hand, the problem of language cognition and meaning consensus is particular to the human condition and foreign to finite-state machines. Should Turing have wanted to give an example of machine intelligence as opposed to human thinking, which machines can imitate, perhaps it would have been instructive to invert the game of machines imitating humans, and have humans imitate machines to illustrate the procedural functions of machine logic. Such an illustration could suggest that difference might be one of degrees. As I have tried to illustrate above, this is precisely what Turing does.

The explicit meaning of imitation in Turing's game indicates the diegetic (gameinternal) action of a computer programmed to imitate human behavior. What generally goes unnoticed by the engaged reader willing to play along with Turing's language games is the quality of change in his substitutions: what was initially an ambiguous language-game question becomes a programmatic empirical exercise in machine behavior. Where an exercise in cognitive reflection on the possibility of thinking machines may only end in an infinite regress of terminological distinction and subjective association (this is how the Turing Test conventionally functions); with the clearly structured set of variables and procedural instructions for performing tasks as part of an equation, the rules for the imitation game generate quantifiable results that may be evaluated and activated subsequently for further use.

If the imitation game sets parameters that frame machines doing as humans do, by turning the original question into a schematic problem with programmatic instructions and quantifiable data output, it also does the opposite: humans imitating computational programmatic logic. This type of quick-witted role reversal is characteristic of Turing's ludic discursive style: "we wish to exclude from the [category of] machines men born in the usual manner;" (Turing 435). It is perhaps no wonder that Turing's conceptual machines are programmed with similar capacities to relativize a task with a selfreflexive, self-referential style and tone that sometimes sound very much like sarcasm: 
Interrogator's Question: "Please write me a sonnet on the subject of the Forth Bridge" Answer: "Count me out on this one. I never could write poetry." (Turing 434)

From this perspective, one is tempted to wonder whether Turing, conjoining the infinite regress of natural-language cognition and programmatic logic of machine intelligence, incorporates by implication a variation on his initial query: can machines have a sense of humor? Thus articulated, the question precludes the possibility that machines cannot think. Moreover, readers are left to consider whether it is a human or a machine generating this answer. As such, the reader is already engaged in a potential imitation game and uncertain about who speaks. If it were a machine response, as it could conceivably be, would we not assume it is able to imitate humor?

In yet another turn of ludic trickery, Turing admits that he is not really interested in posing the question can machines think? For Turing, machine intelligence is a foregone conclusion; one that he claims will become evident to a broader public in the future:

The original question, 'Can machines think?' I believe to be too meaningless to deserve discussion. Nevertheless I believe that at the end of the century the use of words and general educated opinion will have altered so much that one will be able to speak of machines thinking without expecting to be contradicted. (Turing 442)

If Turing provides a doubly recursive analogy for human intelligence via human programmability, his conceptual machinery also provides analogies for future states of human-machine interaction and epistemic shift. Taking the paper as a whole into consideration, it strikes me that "Computational Machinery" might be understood as conjunctural storytelling in its attempt to make what the author perceives to be a future episteme intelligible to the episteme of his time, even if by trickery. In this same paper, Turing narrates a fictional future of digital computing and computer processing units as interchangeable universal machines, predicting their mass dissemination and subsequent cultural naturalization; thus writing the script of our current technosocial transitions toward inclusive network computational systems.

The status of intelligence is currently being revised alongside the status of natural language as they balloon beyond the domain of human cognition. Hidden in plain sight, Turing's explication of human agency transformed into a prosthetic value of an HMI algorithm has written the rules for a conceptual experiment in which mass human agency is technologized in the production of post-anthropocentric narrative cognition. 
Implicit in Google's 2015 rebranding as Alphabet is Turing's next great feat of foresight: to have foreseen free cognitive labor as a consensual undertaking of humanmachine interaction in a new order of numerical narrativity.

\section{Digitality - Google's Names}

On August 10, 2015 Google announced plans to create the holding company Alphabet Incorporated. Explaining the company's motives in the official blog "G Is For Google," co-founder and CEO Larry Page comments on name choice: "We liked the name Alphabet because it means a collection of letters that represent language, one of humanity's most important innovations, and is the core of how we index with Google Search! We also like that it means alpha-bet (Alpha is investment return above benchmark), which we strive for!" (Google Inc. 2015). Corporate branding, as we know, entails the creation of signs that become imbued with meaning, allowing the public to identify a company and its products, and to establish a collection of associations. By commenting on what is attractive about the brand name Alphabet, the blog's readership is already being urged to associate Google's new parent company with notions of language, humanity, innovation, and capital growth. While this seems a logical tactic, the gestural relation to specificities of the technosocial moment is oddly, if somewhat obviously, negotiated.

Facile answers to the question of why to restructure and rebrand in 2015 are evident in the blog announcement and reiterated in news media, where priority was given to creating financial and managerial transparency. As for the name, Alphabet is pre-coded with useful associations: it familiarly signifies innocence, possibility, ingenuity, knowledge and community. Tactically speaking, the establishment of Alphabet enables Google to maintain brand identity for its core businesses, and at the same time to dissociate from these where useful. Google's restructuring and rebranding thus also marks a shift in the company's history, allowing us to reflect on how it perceives its own temporality. Read through the lens of conjunctural storytelling, rebranding reflects shifts in the status of discursive knowledge at a specific moment of technosocial transition, where the creation of economic value coincides in new ways with the creation of discursive value.

\section{Rethinking Click Linking}

Established in 1996 by Stanford University graduate students Larry Page and Sergey 
Brin and incorporated two years later, Google has played a major role in the revolutionary transformation of numerous economies (financial, social, political, etc.) through its reorganization of information economies. While we continue to think of the current techno-epistemic moment in terms of the information age, characterized by digital information and communication technologies, it is the algorithm - a medium for organizing information, intention and action - that makes information intelligible and gives it specific value. Algorithms constitute the substratum of economic routine; they bend to them our cognitive habits and enfold discursive practices. Algorithms act across the exogenous landscapes humans and machines move in and co-inhabit. They are the native language and logic of the media ecologies through which cognition and communication take place. Plotting and structuring technosocial trajectories of the present, algorithms redistribute prior distributions of the sensible, and they will determine technosocial change in the future beyond what is now comprehensible. When compelled to place a finger on the period's defining moment of departure, many will point to the PageRank (PR) algorithm that grew out of the Stanford Digital Library project.

Originally intended for archiving and indexing the entirety of human knowledge on textual record, the PR algorithm was a crucial turn in the automation of cognitive inquiry. In its partial extensions of Foucault's thick textuality and the empirical logic of cross-referential citation, PageRank's indexing function significantly improved automated search techniques in Google's moment of ascension by narrowing the scope of relevant associations. Mediated by the PR algorithm, the associative linking between search terms and knowledge sites has been central to effective algorithmic labor and, thus, company success.

Twenty years ago, the brand name Google signaled a future where numeric computation would structure a brave new informational economy of individualized advertising in e-commerce. Now, the brand name Alphabet suggests a future where the signifying, associative processes that characterize natural-language cognition will structure the new knowledge economy of language-based research and development; an economy where not only humans are intelligent. As stated in the company's 2017 fiscal report, revenues are still generated "primarily by delivering both performance advertising and brand advertising" (Alphabet 2017, 4). However, the same competitive advantages that have allowed Google "to dominate the online advertising industry" (Jurevicius 2018) are now allowing Alphabet to lead the intelligence race: "Across the 
company, machine learning and artificial intelligence (AI) are increasingly driving many of our latest innovations" (Alphabet 3). The status of algorithmic work has not diminished for Alphabet, but it has changed. Its import for Google's breakthrough to market dominance in search technologies, their undisputed command of e-commerce and economic influence through advertising technologies, and their continued access to and generation of pattern-behavior user habit as an essential resource are directly relative to algorithmic labor in current human-machine interaction. The difference, as noted, is in the status of language-based knowledge, which has rapidly transitioned from a (significant) surplus value automatically generated through core practices, to a most precious resource relative to where the company is steering core developments.

\section{Understanding Your Context}

In a 2014 TED talk, Page reflected on Google's original mission to "organize the world's information and make it universally accessible" (Page/Rose 2014), comparing it to a newer vision of strategic development: "computing is kind of a mess. Your computer doesn't know where you are, it doesn't know what you're doing, it doesn't know what you know. And a lot of what we try to do recently is just make your devices work, make them understand your context - Google Now knows where you are, knows what you might need. So really I think computing, where it can understand you and understand that information - we really haven't done that yet" (ibid.) Elements of Turing's conjunctural storytelling carry over here. First, the question of human cognitive habit is minimally veiled as a placeholder for considering the future of machine intelligence. Next, a strategy of rhetorical deflection and deception is evident: in 2014, your computer knew very well where you were and what you might need (or want). These were the company's core competencies. Smart algorithms were programmed to recognize, categorize and dynamically archive patterns of language cognition left as traces in the ether. As such, HMI communication and natural-language (re-)cognition are equally at stake here. But if this string of deceptive claims is a feint, there is nothing false in the question of helping machines to "understand your context".

While machine intelligence has been a core competence and focus from the beginning, the company interests were invested in significantly different ways previous to the current machine-learning boom. Recent development of Neural Turing Machines and Recurrent Neural Networks mark a reorganization of computational knowledge cultures; and as machines make leaps in natural-language cognition, they are increasing 
responsible for high-level decision-making processes and task execution. Smart machines now enjoy degrees of autonomy that were unimaginable some few years ago. Whatever assumptions are made about value in current HMI data economies, if they are not understood as a resource for advances in machine learning, the assumption is amiss.

Fifteen months after Google announced plans to create the holding company Alphabet Incorporated, The New York Times ran an article announcing the "Great A.I. Awakening" (Lewis-Kraus 2016). According to the author, the advanced technologies in machine learning that had transformed Alphabet's language services platform were now "poised to reinvent computing itself" (ibid.). Here we glimpse the meaning of Alphabet that was implicit all along, but subordinated under the other logics of nominal distinction. If the exclamatory fervor of the Times piece has a touch belatedness, a circular logic is also implicit in its central claim. With Translate as an intelligencedriven platform, and with the current state of computational technology underwritten by task-specific programing for data processing qua automated reasoning (i.e. algorithms), the logic might be read as follows: machine intelligence has transformed itself and will reinvent itself. But this is the point.

On the one hand, systemic reflexivity as a transformative operation is at stake. Human activity constitutes an important part of HMI computational logic and algorithmic labor, though human users are to be associated with process in the production of value this time round; not necessarily with its telos in the first instance, as the case was with e-commerce advertising technologies (Google's AdWords and AdSense). On the other hand, these transformative-reflexive operations generate resources that are only secondarily intelligible for humans: through the dramatically improved accuracy of Google's translation services as of mid- to late 2016, for example. Not only do intelligent machines understand the contexts of where you are and what you want; they can now communicate for you what you think you might like to say in a language whose cognitive patterns of symbolic association remain completely foreign to you. Greetings to John Searle from the Chinese room: the fundamental point in present technosocial transition is not the programmatic capacity for choosing a proper character set to produce an accurate iteration of natural language use. Searle's argument was that this could be achieved without proper command or 'knowledge' of the language (cf. Searle 1980). Accurate translation is a symptom, not a cause. If the mise-en-scene of current HMI intelligence is neural-network machine learning that reads and interprets 
patterns of anthropomorphic associative behavior, then its mise-en-abyme is naturallanguage cognition and the ambiguousness of words.

In the current reversal of economic order, value creation is achieved through HMI's automated capacity to produce narrativity. But with more than consumer goods and monetary gain at stake, the question of purpose is a question of perspective. Depending on the locus of intended agency (human or machine), emphasis in the telos of human use can be placed either on the consumption of information or on its production via consumption. If the popular notion of prosumerism is a consumer that assumes a producer role in hyper-fragmented market economies, with the purpose consuming that which it produces, this is one indication of how inadequate our understandings of human capital and surplus value have been in the current era of HMI labor. The fact that consumers can configure their own computers, design their own cloths or market their own wares on the very platforms at which they consume may be interesting as an articulation of innovative market fragmentation. However, this mistakes the ability to set the table at which one eats for the inclusive processes of producing, preparing, consuming, digesting, discharging and repurposing what is eaten. While memory traces of natural-language cognition are a precious resource in the HMI production of value, the trajectory of value creation extends significantly beyond conventions of economic efficacy in digital commerce, and even beyond finance as an iteration economic modernity.

The value of human capital in the present might be compared to its value in the era with which we began; where the creation of class society is accompanied by a valueeconomy model of human capital oriented toward productive labor power. In network society, human capital is once again a highly valuable resource; particularly in its capacity of an operator interacting with machines for mass-production. We have thus uncannily returned to the era of early industrialism: but instead of leaving the home for the factory, we have taken the factory home as a constant companion.

In seeking to make intelligible a genealogical countermemory inscribed in these conjunctural scenes of technosocial transition, my intention has been to historicize cognitive and representational economies in our present moment. Each of these conjunctural tales gravitates toward the shared master plot of HMI automation in economic modernity and the subplot of natural-language cognition as a prototechnology that, in a double reversal, identifies human specificity only to undercut it in 
a subsequent turn of thought. With the shared techniques of diegetic framing, feigned closure and discordant narration, these tales perform in some capacity the epistemic shift Foucault identifies as a departure from narrativity; a departure that engenders space for the new man of enlightenment humanism, only to evacuate the same space of being in the very next instance for lack of continuity. This duality and its historical conditions of impasse have typified thought on reflexive modernity.

Characterizing modernity as the "unprecedented amalgam of new practices and institutional forms (science, technology, industrial production, urbanization); of new ways of living (individualism, secularization, instrumental rationality); and of new forms of malaise (alienation, meaningless, a sense of impending social dissolution)," Charles Taylor claimed that the central problem in the empirical study of modernity "has from the beginning been modernity itself" (Taylor 2004). In a manner recalling Shelley and her progeny of disparate identities, Taylor points to the condition of detracted conjuncture as producing "multiple modernities" that "need to be understood in terms of divergent social imaginaries involved" (ibid.). He explains, however, that social imaginaries are not constituted through a set of abstract ideas. In their institutional-like technicity, social imaginaries are "what enables, through making sense of, the practices of society" (ibid.). With real pragmatic sense-making as the affordance par excellence of contemporary technosocial practice, algorithmic agency assumes a place of prominence in the current social imaginary, where disparate modernities converge in novel self-understandings of narrative recursion.

\section{References}

Allen, Graham (2008): Shelley's Frankenstein. London and New York: Continuum, 2008.

Alphabet, Inc. (2017): Form 10-K for the Fiscal Year Ended December 31, 2017. https://www.sec.gov/Archives/edgar/data/1652044/000165204418000007/goog10kq42017.htm

Baldick, Chris (1987): In Frankenstein's Shadow. Oxford: Clarendon Press.

Brinjolfsson, Erik/McAfee, Andrew (2014): The Second Machine Age: Work, Progress, and Prosperity in a Time of Brilliant Technologies. New York: W.W. Norton \& Company.

Foucault, Michel (1998): Aesthetics, Method and Epistemology. Trans. Robert Hurley et al. Ed. James D. Faubian. New York: The New Press.

Fukuyama, Francis (1992): The End of History and the Last Man. New York: Free Press. 
Gardner, Edith (1994): Revolutionary Readings: Mary Shelley's Frankenstein and the Luddite Uprisings. Iowa Journal of Cultural Studies 13, 70-91.

Google Inc. (2015): G is for Google. Google Official Blog, 10 August 2015, http://googleblog.blogspot.ch/2015/08/google-alphabet.html

Habermas, Jürgen (1996): The Philosophical Discourse on Modernity. Trans. Frederick G. Lawrence. Cambridge, MA: MIT Press.

Hobsbawm, Eric (2006): The Age of Revolution 1798 - 1848. London: Abacus.

Hobsbawm, Eric (1996): The Age of Extremes 1914 - 1991. New York: Vintage Books.

Johnson, Barbara (2014). A Life with Mary Shelley. Stanford, CA: Stanford University Press.

Jurevicius, Ovidijus (2018): SWOT analysis of Alphabet (Google). Strategic Management Insight, 17 April 2018, https:/www.strategicmanagementinsight.com/swotanalyses/google-swot-analysis.html

Lewis-Kraus, Gideon (2016): Great A.I. Awakening. The New York Times Magazine, 14 December 2016, https://www.nytimes.com/2016/12/14/magazine/the-great-aiawakening.html

Loren, Scott (2004): What are the implications of the virtual for the human? European Journal of American Culture 23 (3), 173-185.

Loren, Scott (2018): Words as Witness: Remembering the Present in Mary Shelley's Frankenstein. SPELL Swiss Papers in Literature and Language 36, 2018 (forthcoming).

Luhmann, Niklas (1998): Observations on Modernity. Stanford, CA: Stanford University Press.

Montag, Warren (2000): The Workshop of Filthy Creation: A Marxist Reading of Frankenstein. Mary Shelley's Frankenstein: A Case Study in Contemporary Criticism. Ed. Ross C. Murfin and Johanna Smith. New York: St. Martin's Press, 384395.

Page, Larry/Rose, Charlie (2014): Larry Page at TED2014: Where's Google going next? https://www.ted.com/talks/larry_page_where_s_google_going_next

Rogers, Brett/Stevens, Benjamin (2012): Classical Receptions in Science Fiction. Classical Receptions Journal 4 (1), 1 May 2012, 127-147.

Searle, John (1980): Minds, Brains, and Programs. The Behavioral and Brain Sciences 3, 1980. Cambridge: Cambridge University Press.

Shelley, Mary (1994): Frankenstein. London: Penguin Books.

Shishido, David (2011): Apotheosis Now: A Hegelian Dialectical Analysis of Mary Shelley's Frankenstein. Berkeley Undergraduate Journal 24 (3), 111-126. 
Taylor, Charles (2004): Modern Social Imaginaries. Durham and London: Duke University Press.

Turing, Alan (1950): Computing Machinery and Intelligence. Mind, October 1950, 433-460.

Vincent, James (2018): Goodbye Google Research, hello Google AI. The Verge, 8 May 2018, https://www.theverge.com/2018/5/8/17330290/google-ai-research-division-rebranding

Warwick, Kevin/Shah, Huma (2016): Turing's Imitation Game: Conversations with the Unknown. Cambridge: Cambridge University Press.

Zakharieva, Bouriana (1996): Frankenstein of the Nineties: The Composite Body. Canadian Review of Comparative Literature, September 1996, 739-752. 